\title{
THE ISSUE OF MACROECONOMIC CLOSURE REVISITED AND EXTENDED*
}

\author{
Ernő ZALAI - Tamás RÉVÉSZ \\ (Received: 5 May 2014; revision received: 10 September 2015; \\ accepted: 15 October 2015)
}

Léon Walras (1874) had already realised that his neo-classical general equilibrium model could not accommodate autonomous investments. In the early 1960s, Amartya Sen analysed the same issue in a simple, one-sector macroeconomic model of a closed economy. He showed that fixing investment in the model, built strictly on neo-classical assumptions, would make the system overdetermined, and thus one should loosen some neo-classical conditions of competitive equilibrium. He analysed three not neo-classical "closure options", which could make the model well-determined in the case of fixed investment. His list was later extended by others and it was shown that the closure dilemma arises in the more complex computable general equilibrium (CGE) models as well, as does the choice of adjustment mechanism assumed to bring about equilibrium at the macro level. It was also illustrated through several numerical models that the adopted closure rule can significantly affect the results of policy simulations based on a CGE model.

Despite these warnings, the issue of macro closure is often neglected in policy simulations. It is, therefore, worth revisiting the issue and demonstrating by further examples its importance, as well as pointing out that the closure problem in the CGE models extends well beyond the problem of

* The research underlying this paper was made possible by the support of the European Commission (AROP projects), personally of Juan Carlos Ciscar (EC's JRC-IPTS) and of the Centre for Public Affairs Studies at Corvinus University of Budapest, for which we express our gratitude.

Ernö Zalai, corresponding author. Professor at the Department of Mathematical Economics and Economic Analysis, Faculty of Economics, Corvinus University of Budapest.

E-mail: erno.zalai@uni-corvinus.hu

Tamás Révész, Research fellow at the Department of Mathematical Economics and Economic Analysis, Faculty of Economics, Corvinus University of Budapest.

E-mail: tamas.revesz@uni-corvinus.hu 
how to incorporate autonomous investments into a CGE model. Several closure rules are discussed in this paper and their diverse outcomes are illustrated by numerical models calibrated on statistical data. First, the analyses are done in a one-sector model, similar to Sen's, but extended into a model of an open economy. Next, the same analyses are repeated using a fully-fledged multi-sectoral CGE model, calibrated on the same statistical data. Comparing the results obtained by the two models it is shown that although they generate quite similar results in terms of the direction and - to a somewhat lesser extent - of the magnitude of change in the main macro variables using the same closure option, the predictions of the multi-sectoral CGE model are clearly more realistic and balanced.

JEL classification indices: C54, C68, O50

Keywords: computable general equilibrium model, closure, neo-classical, neo-Keynesian and structuralist theory of distribution, open economy

\section{INTRODUCTION}

Beginning from the 1980s, a large number of computable general equilibrium (CGE) models have been developed all over the world to study a wide range of economic policy areas and issues in which simpler, partial equilibrium or aggregate macro models would be unsatisfactory. CGE models have become standard tools in studying a variety of policy issues, including tax policies, energy and environmental policies, to evaluate the impact of EU cohesion policy and so on. ${ }^{1}$

It had been realised already by Léon Walras (1834-1910), the father of neoclassical general equilibrium models, that in a multi-sector model, built strictly on neo-classical assumptions, there was no room for autonomous investments. Despite the early appearance of the problem, the discussion of the issue is usually traced back only to Sen (1963), who analysed this problem with a simple one-sector model, in which he showed that in the neo-classical realm investments have to be a variable, adjusting freely. He then presented three non-neo-classical adjustment mechanisms to illustrate how one could fix investments in an otherwise neo-classical model.

Sen's analysis was later extended by Taylor - Lysy (1979) who discussed a wider range of closure alternatives. Dewatripont - Michel (1987) analysed the microeconomic basis of the closure problem in the context of temporary competitive equilibrium. Some numerical investigations ${ }^{2}$ made it clear that the choice of

1 From the vast literature on CGE models, we refer to the books of Dervis et al. (1982), Shoven Whalley (1992), Bergman et al. (1990) and Hertel (1997).

2 See, for example, Rattsø (1982), Taylor (1990), Decaluwe et al. (1988), Robinson (1991, 2006) and Thissen (1998). 
macro closure can significantly affect the policy simulation results obtained from a CGE model.

Despite these early warnings, the issue of macro closure is mostly neglected in policy simulations. It is seldom analysed how sensitive the CGE simulation results are depending on what closure option is chosen. It is, therefore, worth revisiting the issue and demonstrating its importance by further theoretical and numerical examples. It is also important to point out that the closure problem extends beyond the treatment of autonomous investments. The problem of how to close a CGE model arises in other areas as well, because, as a rule, the number of potential variables exceeds the number of equations which can be formulated on the basis of trustworthy and operational theories.

Monetary and financial forces can be treated at most in an ad hoc fashion in the CGE models; seldom are real dynamic considerations included in them. Attempts to extend the models in these directions make them less tractable and less reliable. It is "safer" to set the expected magnitude of certain economic variables exogenously rather than determining them endogenously by using formulas questionable on conceptual or empirical grounds. Thus, the model builder has to fix the value of some potential macroeconomic variables, i.e., has to choose which variables will be endogenous and which exogenous (fixed).

In our paper, we generalise first Sen's model to a one-sector model of an open (rather than closed) economy, in which the single product has differentiated varieties, which are less than perfect substitutes for each other. This brings the onesector model closer to the multi-sectoral CGE models. Then, based on the related literature, Sen's analysis is extended to different, characteristic closure alternatives. The diversity of outcomes yielded by different closures is illustrated by numerical simulations based on a model calibrated using Hungarian statistical data. In the second part of the paper, the same analysis is extended to a fullyfledged CGE model, including taxes/subsidies, an elaborated income distribution scheme, distinguishing five production sectors and three groups of households, calibrated on the same data set. Comparing the results of similar simulation runs, based on the same closure option and assuming the same shock, will highlight not only the qualitative similarities, but also the significant quantitative differences between the results achieved by the aggregated macroeconomic and the multisectoral CGE model. 


\section{A ONE-SECTOR GENERAL EQUILIBRIUM MODEL ${ }^{3}$}

In a one-period, multi-commodity model of a closed economy, with investment and capital goods, Walras (1874) defined the pricing rule assuming equal (net) rates of return on the various capital goods. ${ }^{4}$ The rest of the equations of his general equilibrium model described the supply-demand identities. Walras had to realise that in such a model, investment had to be assumed to adjust freely, to become a residual variable, as it would adjust to savings.

Three basic and two composite commodity varieties of the same single product are differentiated in our model: commodity produced and sold at home, exported and imported, its composite domestic output and its composite supply on domestic market. The volume (use value) of the composites of differentiated basic products is measured by monotone increasing, linear homogeneous (aggregation) functions. Unlike Sen, we take into account its intermediate use in production too.

Output capacity is defined by a nested production function of Johansen type, as common in CGE models. Labour $(L)$ and capital $(K)$ are assumed to be imperfect substitutes, jointly determining the output capacity by a linear homogeneous production function, $F(L, K)$. In our numerical model, it will be represented by a constant elasticity of substitution (CES) function. The composite output $(X)$ is divided between domestic $\left(X^{\mathrm{h}}\right)$ and export $(Z)$ supply by means of a constant elasticity of transformation (CET) function, $X=X\left(X^{\mathrm{h}}, Z\right)$. Reexport, as usual, is left out of consideration. The composite home supply $\left(X^{\mathrm{hm}}\right)$ of the commodity produced at home $\left(X^{\mathrm{h}}\right)$ and imported $(M)$ is defined by a CES aggregation function, $X^{\mathrm{hm}}=X^{\mathrm{hm}}\left(X^{\mathrm{h}}, M\right)$.

This means that five commodity prices have to be introduced: the user's price on the domestic $\left(p^{\mathrm{h}}\right)$ and the world market $\left(p^{\mathrm{we}}\right)$, the world market price of the imported good $\left(p^{\mathrm{wm}}\right)$, the producer's price of the composite output $\left(p^{\mathrm{a}}\right)$, and the users' price of the composite domestic supply $\left(p^{\mathrm{hm}}\right)$. For the sake of simplicity, taxes/subsidies, modifying potentially the prices, are disregarded. Therefore, the domestic equivalents of the world market export and import price are simply $v \cdot p^{\text {we }}$ and $v \cdot p^{\mathrm{wm}}$, where $v$ is the exchange rate.

In the case of import price, we adopt the small open economy assumption, $p^{\mathrm{wm}}$ will be thus an exogenous variable. In the case of export, however, as often assumed in CGE models, its world market price depends on its volume, $p^{\mathrm{we}}=p^{\mathrm{we}}(Z)$. According to neo-classical theory, this would mean that exports are differentiated

3 Using one-sector models for didactic purposes is a quite common and useful practice in the CGE literature too. See, for example, Devarajan et al. (1994) and Robinson (2006).

4 Walras analysed the conditions of equilibrium at different levels of abstraction in various simple models of a closed economy. See Zalai (2004) for more details on Walras' models. 
on the world market by the area of their origin. Each country thus faces a less than perfectly elastic export demand function, and $p^{\text {we }}(Z)$ is the inverse of that demand function.

Neo-classical theory assumes that the wage rate $(w)$ and the rental price of capital $(q)$ have to be equal to the marginal revenue of labour and capital, respectively. The revenue is measured here by the value added, $p^{\mathrm{a}}-p^{\mathrm{hm}} \cdot A$, where $A$ is the constant material input coefficient. In some of the discussed closure rules, however, factor prices will be allowed to adjust freely and depart from their marginal products, while the nonprofit pricing rule will be maintained. Therefore, the equilibrium conditions of production will be formulated in the following way:

$$
\begin{gathered}
X=F(L, K) \quad(1), \quad w / \alpha_{\mathrm{w}}=\left(p^{\mathrm{a}}-p^{\mathrm{hm}} \cdot A\right) \cdot \frac{\partial F(L, K)}{\partial L} . \\
p^{\mathrm{a} \cdot} X=p^{\mathrm{hm}} \cdot A \cdot X+w \cdot L+q \cdot K .
\end{gathered}
$$

Equation (3) determines indirectly the equilibrium rental price of the capital (q), since - by virtue of Euler's theorem and the assumed linear homogeneity of the production function - the well-known nonprofit pricing rule prevails: price (revenue) equals cost. Note also that variable $\alpha_{w}$ in equation (2) plays the role of a switch variable. If $\alpha_{w}$ is fixed at value 1 , then the wage rate will be equal to the marginal revenue of labour, and consequently, the rental price (cost) of capital to its marginal revenue. Otherwise, if they are allowed to depart from the respective marginal products, $\alpha_{\mathrm{w}}$ measures simply the ratio of the wage rate to the marginal revenue of labour.

Following Walras' definition, the relation between the cost of capital $(q)$ and the net rate of return on capital $(\pi)$ is $q=\left(r^{\mathrm{a}}+\pi\right) \cdot p^{\mathrm{hm}}$. For convenience, amortisation is disregarded $\left(r^{\mathrm{a}}=0\right)$, thus, this relationship reduces to $q=\pi \cdot p^{\mathrm{hm}}$.

The prices of the composite commodities are determined based on the assumption that their composition is always optimal. In the case of domestic/export composite, total revenue $\left(p^{\mathrm{h}} \cdot X^{\mathrm{h}}+v \cdot p^{\mathrm{we}} \cdot Z\right)$ is maximised, in the case of domestic/ import composite, total cost $\left(p^{\mathrm{h}} \cdot X^{\mathrm{h}}+v \cdot p^{\mathrm{wm}} \cdot M\right)$ is minimised. These assumed optimisations can be represented by the following first order necessary conditions:

$$
\begin{gathered}
X=X\left(X^{\mathrm{h}}, Z\right) \quad(4), \quad p^{\mathrm{h}}=p^{\mathrm{a}} \cdot \frac{\partial X\left(X^{\mathrm{h}}, Z\right)}{\partial X^{\mathrm{h}}} \quad(5), \quad v \cdot p^{\mathrm{we}}=p^{\mathrm{a}} \cdot \frac{\partial X\left(X^{\mathrm{h}}, Z\right)}{\partial Z}, \\
X^{\mathrm{hm}}=X^{\mathrm{hm}}\left(X^{\mathrm{h}}, M\right)(7), \quad p^{\mathrm{h}}=p^{\mathrm{hm}} \cdot \frac{\partial X^{\mathrm{hm}}\left(X^{\mathrm{h}}, M\right)}{\partial X^{\mathrm{h}}} \\
v \cdot p^{\mathrm{wm}}=p^{\mathrm{hm}} \cdot \frac{\partial X^{\mathrm{hm}}\left(X^{\mathrm{h}}, M\right)}{\partial M}
\end{gathered}
$$


where the composite prices ( $p^{\mathrm{a}}$ and $p^{\mathrm{hm}}$ ) are, as a matter of fact, the Lagrangian multipliers corresponding to the respective optimisation problems.

Condition (6), however, has to be modified, because we assume that export demand is less than perfectly elastic. $p^{\text {we }}$ defined by $p^{\text {we }}(Z)$, the inverse demand function, will thus appear instead of $p^{\text {we }}$. The assumption would imply a potentially monopolistic position for the exporters, which could be exploited by means of socalled optimal tariffs (see, for example, Limão 2008). In CGE models, designed for practical uses, it would not be realistic to take this theoretical possibility into consideration and price-taker agents are assumed. The introduction of less than perfectly elastic export demand functions serve only the purpose to restrain priceinduced changes in the volume of export and vice versa.

Equations (1)-(9) define the equilibrium conditions for the supply of commodities for export and domestic use, the demand for imports as well as the market clearing commodity prices. They have to be completed yet with equations describing the income (re)distribution and final demand side of the model.

We will make use of simplifying assumptions in formulating the various budget and behavioural constraints.

$$
\begin{gathered}
p^{\mathrm{wm}} \cdot M-p^{\mathrm{we}}(Z) \cdot Z=D_{\mathrm{e}} \quad(10), \quad p^{\mathrm{hm}} \cdot G+S^{\mathrm{g}}=\tau \cdot(w \cdot L+q \cdot K), \\
p^{\mathrm{hm}} \cdot C+S^{\mathrm{p}}=(1-\tau) \cdot(w \cdot L+q \cdot K) \quad(12), \quad S^{\mathrm{p}}=(1-\tau) \cdot\left(\sigma_{\mathrm{w}} \cdot w \cdot L+\sigma_{\mathrm{k}} \cdot q \cdot K\right) .
\end{gathered}
$$

Equation (10) defines the trade balance deficit $\left(D_{\mathrm{e}}\right)$, in fact, the net savings of foreigners, since non-trade related transfers are neglected in our model. Equation (11) is the budget balance of the government, where $G$ denotes public consumption and $S^{\mathrm{g}}$ net public savings. In this model, for the sake of simplicity, the government is assumed to collect revenue only from income tax, ${ }^{5}$ by means of a uniform tax rate $(\tau)$ applied to both labour and capital income. Equation (12) represents the budget balance of the households, where $C$ denotes private consumption. On the left-hand side, one can see the sum of the value of private consumption $\left(p^{\mathrm{hm}} \cdot C\right)$ and net private savings $\left(S^{\mathrm{p}}\right)$, on the right one, the formation of disposable (net) income. $S^{\mathrm{p}}$ is determined by equation (13), assuming different savings ratios $\left(\sigma_{\mathrm{w}}, \sigma_{\mathrm{k}}\right)$ in the case of labour and capital income.

The commodity balance on the home market takes the following form:

$$
X^{\mathrm{hm}}=A \cdot X+C+G+I
$$

where $I$ denotes investment.

5 Distinguishing consumer's price from general user's price, income tax could be replaced by consumption tax. 
By routine transformations, it can be shown that equations (1)-(12) and (14) imply

$$
p^{\mathrm{hm}} \cdot(C+G+I)=w \cdot L+q \cdot K+v \cdot D_{\mathrm{e}} .
$$

This means that final expenditure will be always equal to total income (Walras' Law) and investment to savings. Therefore, in most related papers, including Sen's seminal paper itself, the reader finds equation $p^{\mathrm{hm}} \cdot I=S^{\mathrm{p}}+S^{\mathrm{g}}+v \cdot D_{\mathrm{e}}$ instead of (14).

The real rate of exchange is defined as the ratio of the foreign to the domestic value of the produced commodity, i.e., as the domestic cost of earning one unit of foreign exchange:

$$
v_{\mathrm{r}}=v \cdot p^{\mathrm{we}}(Z) / p^{\mathrm{h}} .
$$

The above 15 equations define the skeleton of the general equilibrium model that will be used later and we will refer to it as the basic model. The model will be well-determined if the number of variables and equations are equal. The potential (endogenous) variables exceed the number of equations, since at least the following 25 categories could be chosen as variables, depending on our assumptions: $I, L, K, X, X^{\mathrm{h}}, X^{\mathrm{hm}}, Z, M, C, G, p^{\mathrm{a}}, p^{\mathrm{h}}, p^{\mathrm{hm}}, p^{\mathrm{wm}}, w, w_{\mathrm{r}}=w / p^{\mathrm{hm}}, \alpha_{\mathrm{w}}, q, v, v_{\mathrm{r}}, S^{\mathrm{p}}, S^{\mathrm{g}}, \sigma_{\mathrm{w}}$, $\sigma_{\mathrm{k}}, \tau$. We will therefore refer to them as variables, to distinguish them from the parameters, which will be always constant.

\section{MACRO CLOSURE OPTIONS IN THE ONE-SECTOR GENERAL EQUILIBRIUM MODEL}

The actual choice of model specification, i.e., the closure rule, decides which critical macro variables will remain endogenous and which become exogenous in a given model. $X, X^{\mathrm{h}}, X^{\mathrm{hm}}, Z, M, C, p^{\mathrm{a}}, p^{\mathrm{h}}, q, v, S^{\mathrm{p}}$, and $S^{\mathrm{g}}$ (12 altogether) will be, as usual, endogenous in each closure to be discussed below. At the same time, available capital $(K)$, public consumption $(G)$, world market import price $\left(p^{\mathrm{wm}}\right)$, and the savings rates $\left(\sigma_{\mathrm{w}}, \sigma_{\mathrm{k}}\right)$ will be fixed in all versions, although they could be endogenous variables in certain models. Either foreign savings $\left(D_{\mathrm{e}}\right)$ or the real rate of exchange $\left(v_{\mathrm{r}}\right)$ will be fixed in each closure version, too. The first case is perhaps closer to a neo-classical setup, treating foreign exchange as a scarce resource, similarly to labour and capital. As will be seen, the two cases can lead to considerably different results.

The general price level has yet to be set exogenously. It will be fixed by $p^{\mathrm{hm}}=1$, in which case $w$ will be the nominal as well as the real wage rate $\left(w_{\mathrm{r}}=w / p^{\mathrm{hm}}\right)$, 
whereas, since $r^{\mathrm{a}}=0$, the cost of capital $(q)$ will represent at the same time the rate of return $(\pi)$, because $q=\pi \cdot p^{\mathrm{hm}}=\pi$ (their dimensions remain though different, $\pi$ refers to the value, $q$ to the volume of capital).

The basic model, discussed so far, contains 15 equations and only 12 variables have been chosen as endogenous ones so far. Three additional endogenous variables should thus still be chosen from among the remaining potentially endogerous variables $\left(I, L, w, \alpha_{\mathrm{w}}, v_{\mathrm{r}}\right.$ or $\left.D_{\mathrm{e}}, \tau\right)$ to close the model. We start the discussion of possible closure rules with the four alternatives analysed by Sen in his simpler model of a closed economy. Table 1 provides a useful summary of various closure rules to be discussed.

Table 1. Summary of various closure rules in the one-sector model

\begin{tabular}{|c|c|c|c|c|c|c|c|c|}
\hline & 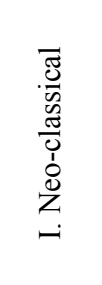 & 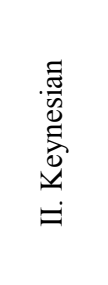 & 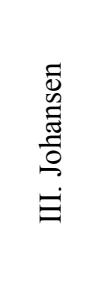 & 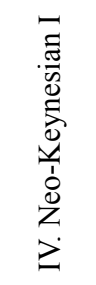 & 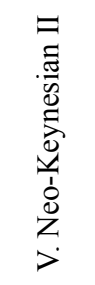 & 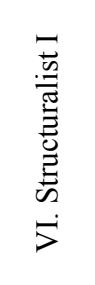 & 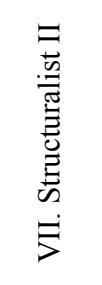 & 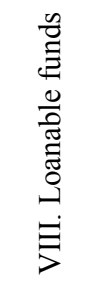 \\
\hline I & end. & exog. & exog. & exog. & exog. & end. & end. & end. \\
\hline $\mathrm{L}$ & exog. & end. & exog. & exog. & end. & end. & end. & exog. \\
\hline $\mathrm{w}$ & end. & end. & end. & end. & exog. & exog. & end. & end. \\
\hline$\alpha_{w}$ & 1 & 1 & 1 & end. & end. & end. & end. & 1 \\
\hline$v_{\mathrm{r}}$ & $\begin{array}{l}\text { exog./ } \\
\text { end. }\end{array}$ & $\begin{array}{l}\text { exog./ } \\
\text { end. }\end{array}$ & $\begin{array}{l}\text { exog./ } \\
\text { end. }\end{array}$ & $\begin{array}{l}\text { exog./ } \\
\text { end. }\end{array}$ & $\begin{array}{l}\text { exog./ } \\
\text { end. }\end{array}$ & $\begin{array}{l}\text { exog./ } \\
\text { end. }\end{array}$ & $\begin{array}{l}\text { exog./ } \\
\text { end. }\end{array}$ & $\begin{array}{l}\text { exog./ } \\
\text { end. }\end{array}$ \\
\hline$D_{\mathrm{e}}$ & $\begin{array}{l}\text { end./ } \\
\text { exog. }\end{array}$ & $\begin{array}{l}\text { end./ } \\
\text { exog. }\end{array}$ & $\begin{array}{l}\text { end./ } \\
\text { exog. }\end{array}$ & $\begin{array}{l}\text { end./ } \\
\text { exog. }\end{array}$ & $\begin{array}{l}\text { end./ } \\
\text { exog. }\end{array}$ & $\begin{array}{l}\text { end./ } \\
\text { exog }\end{array}$ & $\begin{array}{l}\text { end./ } \\
\text { exog. }\end{array}$ & $\begin{array}{l}\text { end./ } \\
\text { exog }\end{array}$ \\
\hline$\tau$ & exog. & exog. & end. & exog. & exog. & exog. & exog. & exog. \\
\hline$c^{\pi}$ & na & na & na & na & na & end. & exog. & na \\
\hline $\mathrm{i}$ & na & na & na & na & na & na & na & end. \\
\hline
\end{tabular}

Notes: end. $=$ endogenous, exog. $=$ exogenous, na $=$ not applicable.

\section{Neo-classical (Walrasian) closure}

In a Neo-classical model, $L$ should be fixed, and both factors of production paid according to their marginal revenue. Thus, $w$ is the endogenous variable and $\alpha_{\mathrm{w}}$ $=1$. As mentioned above, either $v_{\mathrm{r}}$ or $D_{\mathrm{e}}$ will also be an endogenous variable, whereas $\tau$ is a given parameter, influencing the disposable income of the households. Thus, only investment $(I)$ remains to be still missing, 15th endogenous variable. Note, that it is not specified in such a model, what sort of mechanism 
could make the investment adjust to savings. The interest rate is often assumed implicitly to equilibrate savings and investments, which option will appear later in the loanable funds closure.

\section{Keynesian (General Theory) closure}

As indicated earlier, if we want to introduce autonomous investment into the model, we must relax the strict neo-classical conditions. Sen relaxed first the assumption of fixed labour constraint (full employment) by reinterpreting $L$ as the variable level of employment and could thus fix the level of investment instead. Since the wage rate remains determined by the marginal revenue of labour, any increase in the level of employment will go hand in hand with its decrease and the increase of the rate of return on capital, and vice versa, establishing thus the equality between investment and savings. Any exogenous increase in investment (or government expenditure) would generate a Keynesian multiplier effect in such a model.

\section{Johansen closure}

Here Sen was inspired by Johansen's (1960) pioneering CGE model, in which it was assumed that the government could intervene by an appropriate tax policy to secure full employment even in the case of exogenously fixed investment level. In Johansen's model, the supply of both labour and capital was fixed, and marginal pricing rule prevailed. If one adopts these assumptions, output will be determined in the same way as in the case of the Neo-classical closure. If public consumption $(G)$ and investment are also fixed, only the level of private consumption can adjust to reach equilibrium. In this closure, the changing level of tax rate $(\tau)$ is assumed to bring about equilibrium.

\section{Neo-Keynesian closures I (forced savings)}

The fourth and last option discussed by Sen was based on the "forced savings" models of Kaldor (1956) and Pasinetti (1962), which he termed as a Neo-Keynesian closure. Forced savings is a macro closure scenario, in which $\alpha_{\mathrm{w}}$ becomes the endogenous variable instead of the investment level. It is thus assumed that changing real wage could make savings adjust to a fixed level of investment even in the case of full employment.

If one sets the price level by $w=1$, instead of $p^{\mathrm{hm}}=1$, as common in Keynesian models, the output price will become the equilibrating variable. Increasing investment, for example, would drive real wage down, as in the case of the Keynesian closure. Unlike in the latter, however, both the output and the employment level remain unchanged, and the increasing investment crowds out consumption. 


\section{Neo-Keynesian closure II (fixed real wage)}

An alternative closure also with a Keynesian flavour could be to fix the real wage rate and assume the employment level to be the equilibrating variable instead, as in the Keynesian closure. This would combine two Keynesian assumptions, the refusal of the neo-classical idea of full employment as well as the Neo-classical theory of wages.

\section{VI-VII. Structuralist closures}

Structuralist CGE models, designed and used mainly for analysing economic policy options in developing economies, ${ }^{6}$ bring in institutional considerations in describing the behaviour of certain macroeconomic variables. Following Keynes and classical economists, they usually allow for fixed nominal or real wage rate and unemployment (i.e., variable level of employment) and may depart in other aspects too from the neo-classical assumptions. For example, investment can depend on expected future returns, the level of capacity utilisation may vary, various market imperfections are taken into account, and cost-plus-markup price formation is assumed.

We will analyse here a model, in which cost-plus-markup pricing rule is assumed and investment is a function of the net rate of return on capital $(\pi)$ :

$$
I=I(\pi),
$$

where $\pi$ can be interpreted as an indicator of expected future returns.

Cost-plus-markup pricing means that equation (3) is replaced by the following one:

$$
p^{\mathrm{a}} \cdot X=\left(1+\pi_{\mathrm{m}}\right) \cdot\left(p^{\mathrm{hm}} \cdot A \cdot X+w \cdot L\right),
$$

where $\pi_{\mathrm{m}}$ is the profit markup, which replaces the rate of return on capital.

Alternatively, one can simply introduce profit markup as a new variable, together with an additional equation that establishes the relationship between the rate of return on capital and the profit markup. Choosing this option, the following form will be used:

$$
\pi \cdot p^{\mathrm{hm}} \cdot K=p^{\mathrm{a}} \cdot c^{\pi} \cdot X,
$$

where $c^{\pi}=\pi_{\mathrm{m}} /\left(1+\pi_{\mathrm{m}}\right)$, is the ratio of profit in total revenue, replacing $\pi_{\mathrm{m}}$.

It is worth observing that equation (17) can be rewritten as

$$
\pi \cdot p^{\mathrm{hm}} \cdot K=\pi_{\mathrm{m}} \cdot\left(p^{\mathrm{hm}} \cdot A \cdot X+w \cdot L\right)=\frac{\pi_{\mathrm{m}}}{1+\pi_{\mathrm{m}}} p^{\mathrm{a}} \cdot X .
$$

6 For a detailed discussion of the structuralist models see, first of all, Taylor (1990). 
These forms provide an interesting insight into the model. If profit markup $\left(\pi_{\mathrm{m}}\right)$ is fixed, the rate of return on capital moves practically in proportion to $X$, which in turn changes only if $L$ changes into the same direction too. Thus, for example, an increase in investment will lead to an increase in the rate of return on capital, triggering an accelerator effect, in addition to the multiplier effect caused by variable employment level, although the profit markup is fixed.

In the model extended by equations (16) and (17) five further endogenous variables remain to be chosen and their potential list is extended by variable $c^{\pi}$. One cannot, of course, fix both $\pi$ and $c^{\pi}$ at the same time. In the case of the two structuralist closures introduced $I, L$ and $\alpha_{\mathrm{w}}$ are endogenous variables, and $\tau$ remains exogenous. One has thus to choose two more from among $w, \pi_{\mathrm{m}}$ and $v_{\mathrm{r}}$ or $D_{\mathrm{e}}$. We choose either $v_{\mathrm{r}}$ or $D_{\mathrm{e}}$, as before, thus the remaining choice is either the (real) wage rate or the profit markup. In Structuralist closure I the wage rate, in Structuralist closure II the profit markup will be fixed.

\section{The loanable funds closure}

Based on the classical idea that savings can be viewed as the supply of loanable funds and investment the demand for them, one could introduce into the model the real rate of interest $(i)$ as additional variable, and assume that the savings rates, $\sigma_{\mathrm{w}}(i)$ and $\sigma_{\mathrm{k}}(i)$ are increasing, whereas investment, $I(i)$ is a decreasing function of it. In such a model the rate of interest would be the equilibrating variable that makes investment and savings match one another. In that model the private savings identity and the investment function have to be modified as follows:

$$
\begin{gathered}
S^{\mathrm{p}}=(1-\tau) \cdot\left[\sigma_{\mathrm{w}}(i) \cdot w \cdot L+\sigma_{\mathrm{k}}(i) \cdot q \cdot K\right] . \\
I=I(i) .
\end{gathered}
$$

As explained by Taylor (1990), such a closure is subject to at least two serious objections (both emphasised by Keynes already). First, the interest rate, i.e., the rate of return to assets, is in principle determined by stock markets and not by savings and investment flows. Second, the influence of the interest rate on aggregate investment demand is limited by various institutional factors.

\section{The real balances (Pigovian) closure}

Continuing the above comments, the loanable funds approach can be extended into a real balances closure by taking into account wealth effects, in the form of the Pigou (1943) effect or, based on the portfolio model developed by Tobin (1971), introducing interest payments and interest clearing financial asset mar- 
kets. Assuming exogenously given nominal wage and introducing money supply $(M)$ one could define the real balances of the wealth holders $\left(M / p^{\mathrm{hm}}\right)$. If the savings rate depends on the real balance, the real balance effect could work in the same way as the rate of interest in the loanable funds closure.

\section{A NUMERICAL EXAMPLE AND SIMULATION RESULTS}

We selected six characteristic closure rules (I, II, III, V, VI, and VII) to demonstrate the adjustment mechanisms assumed to work in them by means of a numerical model. We used Hungarian statistical data for 2010 to calibrate the model (Hungarian Central Statistical Office 2012, 2013). The database used for calibration is arranged in Table 2, which can be regarded as an Input-Output (I-O) table combined with a Social Accounting Matrix (SAM). Making use of the simple structure of our models, we managed to include the income redistribution into the fourth quadrant of the table.

The base level of all price indeces $p^{\mathrm{a}}, p^{\mathrm{h}}, p^{\mathrm{hm}}, p^{\mathrm{we}}, p^{\mathrm{wm}}$, and that of the nominal foreign exchange rate $v$ were set to 1 in the calibration, which with the observed $L=4$ and $K=200$ factor employments led to the initial values of 3.493 and 0.047 for $w$ and $q$. Calibrated values of some parameters are as follows:

$-\pi_{\mathrm{m}}=0.207 ; \tau=0.212 ; \sigma_{\mathrm{w}}=0.353 ; \sigma_{\mathrm{k}}=0.5$;

- the elasticity of substitution (set exogenously) and the calibrated distribution parameters $\left(a_{*}\right)$ in the CES-CET functions are as follows:

$\operatorname{CES} F\left(\phi, a_{\mathrm{L}}, a_{\mathrm{K}}, r_{\mathrm{L}}, r_{\mathrm{K}}\right)=F(0.5,0.596,0.404,0.0726,3.628)$, where $r_{\mathrm{L}}$, and $r_{\mathrm{K}}$ are the labour and capital coefficients in the base case;

CET $X\left(\sigma, a_{\mathrm{d}}, a_{\mathrm{z}}\right)=X(-2,6.330,53.613)$;

CES $X^{\mathrm{hm}}\left(\mu, a_{\mathrm{h}}, a_{\mathrm{m}}\right)=X^{\mathrm{hm}}(0.5,0.425,0.121)$;

- the price elasticity, $\varepsilon$ in the $p^{\text {we }}(Z)=a_{\mathrm{z}} \cdot Z^{-1 / \varepsilon}$ export demand function, was set at -4 , which means that 1 per cent increase in export volume leads to 0.25 per cent decrease in export price. In most CGE models, somewhat smaller values are used, which yield larger price effects.?

In the case of exports, we assumed that domestic and export supply can be transformed into each other with relative ease (the elasticity of transformation is 2), whereas, in the case of imports, we assumed that they are rather complements than substitutes to domestic products (the elasticity of substitution set at 0.5 ), which means their supply will move in the same direction.

7 The simulation results are rather sensitive to the size of the elasticity, especially in the case of fixed balance of trade. 
In our simulation exercises, we stick always to the rule that the external shock is created by change only in one exogenous variable. In policy simulations made with CGE models, one normally designs a scenario, in which forecasted changes in all important exogenous variables are taken into account and harmonised with each other.

Table 2. The initial data arranged into a combined I-O and SAM table (values in thousand billion HUF)

\begin{tabular}{|c|c|c|c|c|c|c|}
\hline $\begin{array}{l}\text { Expenditures } \\
\Rightarrow \\
\text { Receipts } \Downarrow\end{array}$ & $\begin{array}{c}\text { Commodities } \\
\text { (composition } \\
\text { of sources) }\end{array}$ & Consumers & Government & Investors & $\begin{array}{l}\text { Rest of } \\
\text { the world }\end{array}$ & $\begin{array}{l}\text { Total } \\
\text { receipts }\end{array}$ \\
\hline $\begin{array}{l}\text { Commodi- } \\
\text { ties (deliver- } \\
\text { ies) }\end{array}$ & $\begin{array}{c}p^{\mathrm{hm}} \cdot A \cdot X= \\
31.69\end{array}$ & $\begin{array}{c}p^{\mathrm{hm}} \cdot C= \\
10.85\end{array}$ & $\begin{array}{c}p^{\mathrm{hm}} \cdot G= \\
6.17\end{array}$ & $\begin{array}{c}p^{\mathrm{hm}} \cdot I= \\
4.58\end{array}$ & $\begin{array}{c}v \cdot p^{\mathrm{we} \cdot} \cdot Z= \\
20.37\end{array}$ & 73.66 \\
\hline Consumers & $\begin{array}{l}w \cdot L= \\
13.97\end{array}$ & & & $\begin{array}{c}(1-\tau) \cdot\left(1-\sigma_{\mathrm{k}}\right) \cdot \\
q \cdot K=3.73\end{array}$ & & 17.70 \\
\hline Government & & $\tau \cdot w \cdot L=2.96$ & & $\tau \cdot q \cdot K=2.01$ & & 4.97 \\
\hline Investors & $q \cdot K=9.46$ & $\begin{array}{c}S_{\mathrm{w}}=\sigma_{\mathrm{w}} \cdot(1-\tau) \\
w \cdot L=3.89\end{array}$ & $S^{\mathrm{g}}=-1.20$ & & $\begin{array}{l}v \cdot D_{\mathrm{e}}= \\
-1.83\end{array}$ & 10.32 \\
\hline $\begin{array}{l}\text { Rest of the } \\
\text { world }\end{array}$ & $\begin{array}{c}v \cdot p^{\mathrm{wm}} \cdot M= \\
18.54\end{array}$ & & & & & 18.54 \\
\hline Total outlays & 73.66 & 17.70 & 4.97 & 10.32 & 18.54 & \\
\hline
\end{tabular}

\subsection{The effect of a $5 \%$ increase in the government expenditure under various closures}

We have first simulated the effect of an internal demand shock, assuming a 5\% increase in the government expenditure. We have estimated the results both in the case of fixed real exchange rate and fixed balance of trade. The results are shown in Table 3.

We will analyse in details only the case of fixed real exchange rate, since in the case of fixed balance of trade, the real effects will be very similar, although somewhat sharpened. Savings will behave, of course, differently in the two cases. Foreign savings decrease in the first case and increase in the second. Private savings increase also faster (due to the larger increase of employment) and government savings increase therefore slower.

In the Neo-classical and the Johansen closure, total output and net output for final use, the wage and profit rate, all prices, foreign trade, and foreign savings remain the same as in the base. The increase in government expenditure affects therefore only the distribution of the net output. In the case of the Neo-classical closure, the increase of the government expenditure takes place at the cost of in- 


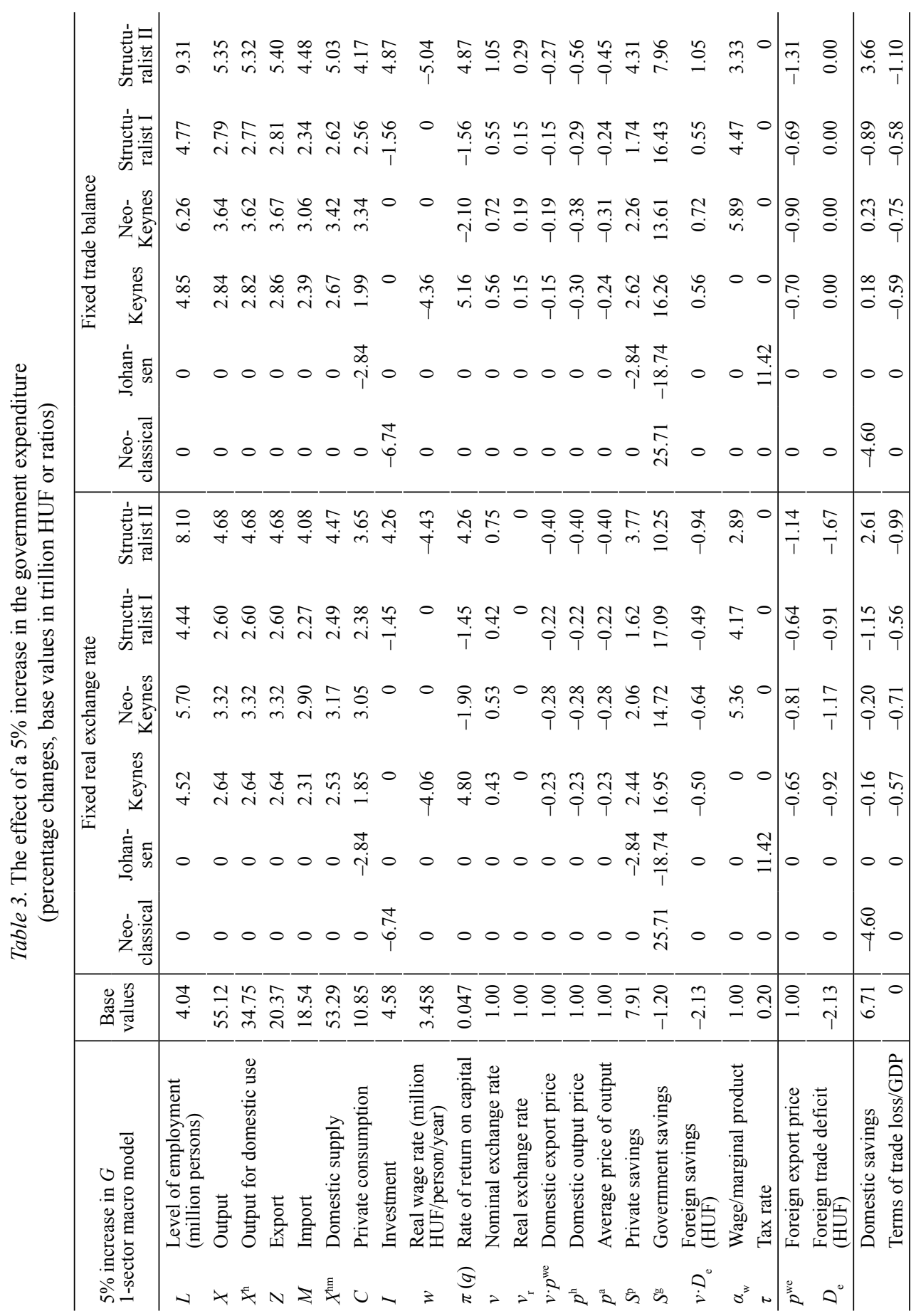


vestment and government savings. In the Johansen closure, government expenditure increases at the expense of consumption, which is enforced by the higher tax rate, which allows at the same time to increase government savings, making up for the decreasing private savings.

In the Keynesian closure, $L$ becomes variable instead of $I$, available labour does not constrain the expansion of production any longer. The increase in the government expenditure creates a multiplier effect: output grows by $2.6 \%$ and employment by $4.5 \%$. The marginal product of labour, consequently the wage rate, decreases by $4 \%$, which in turn increases the rate of return on capital by almost $5 \%$. Despite the falling wage rate, total private income and consumption increases $(1.9 \%)$, multiplying the effect of the autonomous growth of final demand.

With increasing output comes increasing import (2.4\%), which has to be compensated by growing export $(2.6 \%)$, reinforcing also the multiplier effect. Increasing export reduces slightly the price level of export $(0.7 \%)$ and increases the nominal exchange rate $(0.4 \%)$. As a result of the latter, the domestic output price diminishes too $(-0.2 \%)$. Since investment is fixed, savings remain the same, but their composition changes. The government's savings decrease by about $17 \%$, compensated by $2.4 \%$ increase in private and $0.5 \%$ increase in foreign savings.

In the Neo-Keynesian closures, the wage rate is no longer determined by the marginal product of labour $\left(\alpha_{\mathrm{w}}\right.$ becomes endogenous instead of $\left.I\right)$. In its first version, discussed by Sen, $L$ remains fixed, as in the neo-classical closure, in the second, it is let vary at the expense of fixing the real wage rate. ${ }^{8}$ We present only the results of this second, Neo-Keynesian closure II, in which all other aspects are the same as in the Keynesian closure. As a result of fixed real wage rate, total wage fund grows at the same rate as the level of employment $(5.7 \%)$, exceeding the growth rate of the output and the value added $\left(p^{\mathrm{a}} \cdot X-p^{\mathrm{hm}} \cdot A \cdot X\right)$, which grow only by about $3 \%$. As a result, the rate of return on capital decreases (by $2 \%$ ). To make up for the lost savings the level of employment and output has to expand more than in the case of the Keynesian closure. The rest of the changes are similar to those experienced in the case of Keynesian closure.

The structuralist closures depart more drastically from the Keynesian by using markup pricing and incorporating an accelerator effect in addition to the multiplier effect, because investment depends on the rate of return on capital. We used a simple investment function of the following form:

$$
I=I^{0}\left(\frac{\pi}{\pi^{0}}\right)^{\delta},
$$

8 This scenario assumption is somewhat unrealistic since real wage should decrease to some extent to enable employment to increase. But we stick to the rule of changing only one assumption at a time. 
where we have chosen $I^{0}$ and $\pi^{0}$ to be equal to the base values of the investment and the rate of return on capital, and $\delta$, the elasticity parameter to 1 . Since $K$ is fixed, all these mean that investment will change in proportion to capital income. In Structuralist closure I, the (real) wage level is fixed, and the profit markup is free to adjust. The profit markup decreases by $4.5 \%$, the rate of return on capital and investment both by $1.5 \%(\delta=1$ !). One can observe thus a reverse accelerator effect in this case, which slows down the growth, compared to the Neo-Keynesian closure. In Structuralist closure II, the rate of the profit markup is fixed instead of the real wage. The real wage decreases by $4.4 \%$, the rate of return on capital as well as the investment level grows by $4.26 \%$, adding an accelerator effect to the multiplier effect. As a result, employment increases by $8.1 \%$, output by $4.7 \%$, and consumption by $3.7 \%$, indicating thus quite an economic boom.

In Table 3, one can also see how the simulation results are modified by fixing the balance of trade instead of the real exchange rate. This makes foreign currency scarcer than in the previous simulations, therefore, the domestic currency devaluates, increasing the domestic value of the fixed foreign surplus, i.e., decreasing foreign savings. In the case of the Neo-classical and Johansen closure, in which foreign savings remain unchanged, the results do not change either. In the case of the other closures, the decreasing government and foreign savings can be made up only by growing domestic income. Therefore, the economy must grow at a faster rate than in the case of a fixed real exchange rate, resulting in larger terms of trade losses as well.

\subsection{The effect of a $2 \%$ increase in world market import prices under various closures}

In the second series of simulations, we analysed the likely effect of an external shock, represented by a $2 \%$ increase in the world market import prices. As can be seen in Table 4, the difference between the results obtained in the case of a fixed real exchange rate and a fixed balance of trade become larger. At a fixed real exchange rate, the trade balance deteriorates by about $9 \%$ in all closures, which must be compensated by $1.34-1.48 \%$ devaluation if the balance of trade is fixed. This leads to larger changes in relative prices and, consequently, in all volume and income variables as well.

In the case of a fixed real exchange rate, the increasing net foreign savings (resulting from smaller trade sufficit) make up for a large part of the lost income available for domestic use, the changes in final demand are, therefore, less drastic than in the case of fixed balance of trade. In the case of the Neo-classical and Johansen closures, the GDP (affected by terms of trade changes too) drops by 


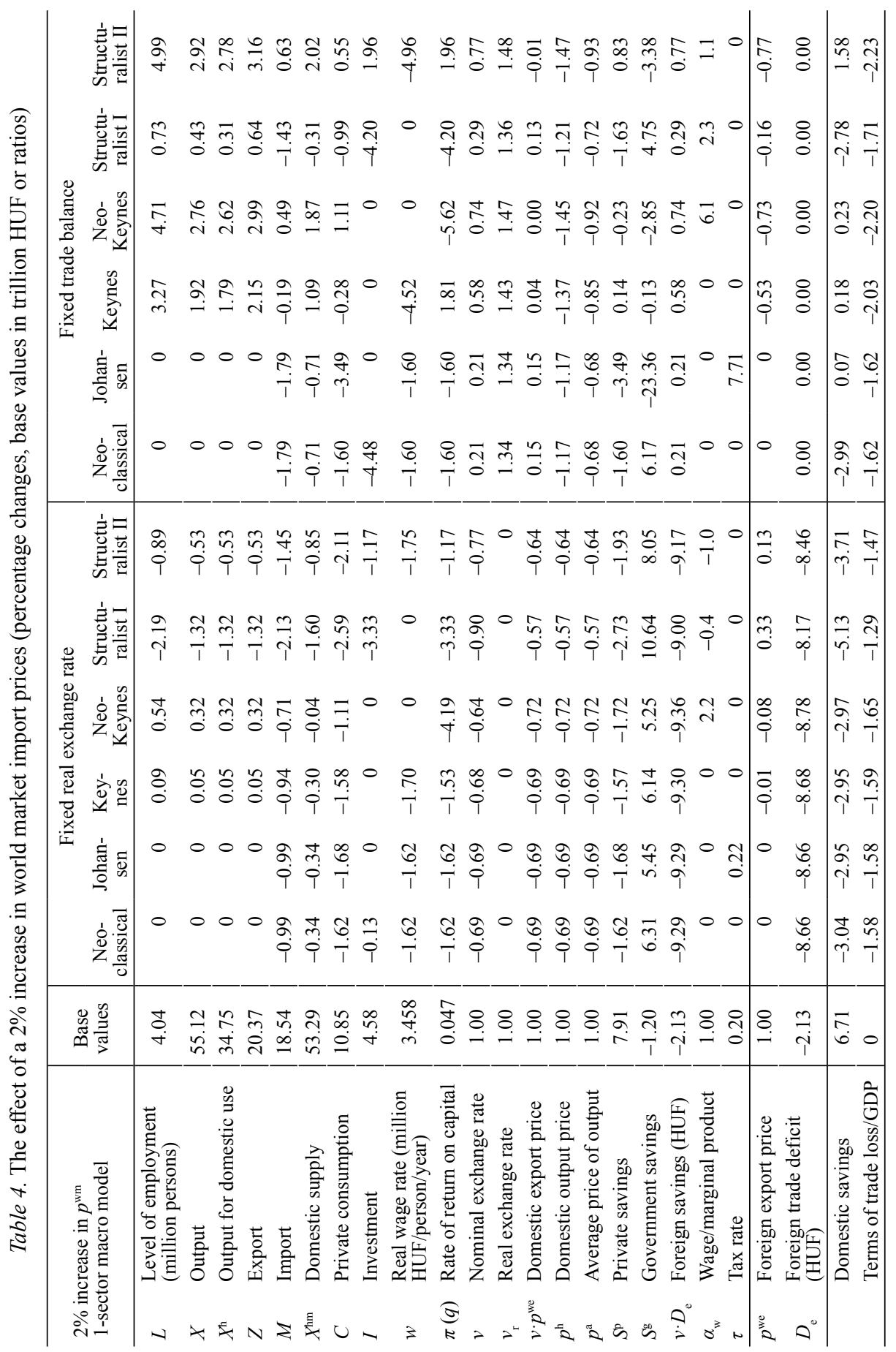


about $1.6 \%$ and both the wage rate and the rate of the return on capital decreases, at roughly the same per cent.

In the Keynesian and Neo-Keynesian closures, the results of the Neo-classical closure are almost reproduced in the case of a fixed real exchange rate. This is due to the fact that the relative prices on the domestic and foreign markets, and consequently, the domestic and foreign supply/demand structures change only slightly. Since government expenditure and investment are fixed, the level of consumption drops as a consequence of diminishing GDP. The case of fixed balance of trade is quite different. The growing real exchange rate increases the share of export and decreases that of import, and the resulting increase of the net export in final demand enhances the multiplier effect. The higher level of employment $(3.3 \%$ and $4.7 \%)$ and consumption strengthen further the multiplier effect, especially in the case of the Neo-Keynesian closure. Increasing export volume is accompanied by falling export price, which increases the terms of trade loss in both Keynesian closures.

In the case of the Structuralist closures, the investment function brings in a negative accelerator effect, when the rate of return on capital drops. This happens in all cases, except for one, the case of structuralist II, with fixed trade balance. There the rate of return on capital and investment increases by close to $2 \%$, creating quite a boom.

\section{MACRO CLOSURE OPTIONS IN A MULTI-SECTORAL MODEL}

\subsection{The structure of a disaggregated CGE model}

We now turn our attention to the issue of closure in multi-sectoral CGE models. We will first review their typical variables and equations, and then replicate the simulation runs made with the one-sector model by means of a fully-fledged multi-sectoral CGE model, developed for the analysis of various policy issues in Hungary.

To make the model as realistic as possible, the household sector is disaggregated into three groups (income terciles), and three main areas of domestic use (private consumption, investment and other areas) are also distinguished, assuming different elasticity parameters determining their import-domestic composition. In addition to disaggregation we use, for practical reasons, somewhat different forms of specification for various functions describing substitution possibilities than in the one-sector model. The detailed representation of the complex tax and income redistribution system also requires a model somewhat different from the stylised model. The export supply functions used in this model are also different 
from the one used in the one-sector model. They may depend, apart from the prices, on the level of output too.

Further on, following the example of recent CGE-models designed for policy analysis, nested CES production functions are used in our model too, in which energy also appears as a production factor substitutable with labour and capital. As a result, wage-induced shifts will be smaller than in the one-sector model. Substitution between various types of energy inputs will be also allowed for in the production function.

In the following brief overview of the model, for the sake of simplicity, we will not present the above-mentioned functions in their concrete parametric form. On the basis of the aggregate macroeconomic model presented earlier, the reader will be able to reconstruct them.

\subsection{The equations of the disaggregated CGE model}

In a multi-sectoral model one has to distinguish commodities and prices by their sectoral origin. We will use $i$ and/or $j$ indices for different sectors, depending on whether it refers to sectoral commodity or activity (for example, $x_{j}, z_{j}, x_{i}^{\mathrm{hm}}, u_{i}, p_{i}^{\mathrm{hm}}$, $p_{i}^{\mathrm{wm}}, p_{i}^{\text {we }}$ and so on).

As will be seen, the equations defining the equilibrium conditions of the supply and pricing side of the model will be practically the same as in the case of the one-sector model, except that we will use their dual and mixed forms, as described earlier, in defining the necessary conditions of equilibrium.

A variable will be associated with each equation. In this way, one can easily check if the model is well defined or not, i.e., whether the number of equations and variables are equal or not. In most cases, the variable associated with the equation is the one standing on its left-hand side. Therefore, it will not be indicated explicitly. If it is another variable, it will be attached to the equation numbers appearing on their right-hand side. For example, (M-01: $\left.k_{j}\right)$ in the case of the first equation.

In the following equation list of the model we preserve, as much as possible, the logic and sequence of the equations of the one-sector model. Therefore, the first block contains the production functions and the derived factor demand equations:

$1=f_{j}\left(l_{j}, k_{j}, e_{j}\right)$

production functions (unit isoquants)

(M-01: $\left.k_{j}\right)$

$l_{j}=l_{j}\left(w_{j} / \alpha_{\mathrm{w}}, q_{j}, p_{j}^{\mathrm{en}}\right) \quad$ labour input coefficient

$e_{j}=e_{j}\left(w_{j} / \alpha_{\mathrm{w}}, q_{j}, p_{j}^{\mathrm{en}}\right) \quad$ aggregate energy input coefficient 
$a_{i j}=a_{i j}\left(p_{s+1, j}^{\mathrm{hmut}}, p_{s+2, j}^{\mathrm{hmut}}, \ldots p_{n, j}^{\mathrm{hmut}}, \mathrm{e}_{j}\right), i \in \mathrm{EN} \quad$ variable input coefficients(M-04)

$p_{i j}^{\mathrm{hmut}}=p_{i}^{\mathrm{ohm}} \cdot\left(1+\tau_{i, j}^{\mathrm{fu}}\right), i \in \mathrm{EN} \quad$ user's price of energy in production

$p_{j}^{\mathrm{en}}=\sum_{i=s+1}^{n} p_{i j}^{\mathrm{hmut}} \cdot a_{i j} / e_{j} \quad$ user price (cost) of aggregate energy,

where $\mathrm{EN}=\{s+1, s+2, \ldots, n\}$ is the index set of energy products.

The following three equations define the composite sectoral outputs:

$x_{j}=x_{j}\left(x_{j}^{\mathrm{h}}, z_{j}\right) \quad$ composition of the sectoral outputs

$(\mathrm{M}-07)$

$z_{j}=r_{j}^{\mathrm{eh}}\left(p_{j}^{\mathrm{h}}, p_{j}^{\mathrm{e}}\right) \cdot x_{j}^{\mathrm{h}} \quad$ exports supply

$p_{j}^{\mathrm{a}}=p_{j}^{\mathrm{h}} \cdot\left(x_{j}^{\mathrm{h}} / x_{j}\right)+p_{j}^{\mathrm{e}} \cdot\left(z_{j} / x_{j}\right) \quad$ (average) producers' prices

$\left(\mathrm{M}-09: p_{j}^{\mathrm{h}}\right)$

By splitting the market of each product into the mentioned three main areas of use, the total supply of domestic and import products on the domestic market is defined as

$x_{i}^{\mathrm{h}}=x_{i}^{\mathrm{oh}}+x_{i}^{\mathrm{ch}}+x_{i}^{\mathrm{bh}} \quad$ decomposition of the domestic supply

$m_{i}=m_{i}^{\mathrm{o}}+m_{i}^{\mathrm{c}}+m_{i}^{\mathrm{b}} \quad$ decomposition of the import supply

The multi-sectoral and use-specific equivalents of equations (7)-(9) are as follows:

$x_{i}^{r \mathrm{hm}}=x_{i}^{r \mathrm{hm}}\left(x_{i}^{r \mathrm{~h}}, m_{i}^{r}\right), \quad$ composite supply by market segments

$m_{i}^{r}=r_{i}^{r \mathrm{mh}}\left(p_{i}^{\mathrm{h}}, p_{i}^{\mathrm{m}}\right) \cdot x_{i}^{r \mathrm{rh}} \quad$ imports supply by market segments

$p_{i}^{r \mathrm{hm}}=\left(p_{i}^{\mathrm{h}} \cdot x_{i}^{r \mathrm{~h}}+p_{i}^{\mathrm{m}} \cdot m_{i}^{r}\right) / x_{i}^{r \mathrm{hm}}$ average domestic users' prices,

where $r=\mathrm{o}, \mathrm{c}, \mathrm{b}$ (c consumption, $\mathrm{b}$ investment, o other areas of use).

In the above equations, $l_{j}\left(w_{j} / \alpha_{w}, q_{j}\right), x_{j}\left(x_{j}^{\mathrm{h}}, z_{j}\right), r_{j}^{\mathrm{eh}}\left(p_{j}^{\mathrm{h}}, p_{j}^{\mathrm{e}}\right), x_{i}^{r \mathrm{hm}}\left(x_{i}^{r \mathrm{~h}}, m_{i}^{r}\right)$ and $r_{i}^{r \mathrm{mh}}\left(p_{i}^{\mathrm{h}}\right.$, $\left.p_{i}^{\mathrm{m}}\right)$ are all dual forms, derived from assumed optimising behaviour.

The auxiliary (sectoral) cost and price variables are as follows:

$w_{j}=\left(1+\tau_{j}^{\mathrm{w}}\right) \cdot w \cdot d_{j}^{\mathrm{w}} \quad$ cost of labour

$q_{j}=p_{j}^{\mathrm{b}} \cdot\left(r_{j}^{\mathrm{a}}+\pi \cdot d_{j}^{\pi}\right) \quad$ Walras' cost of capital,

where 
$p_{j}^{\mathrm{b}}=\sum_{i} p_{i}^{\mathrm{bhm}} \cdot b_{i j} \quad$ price indices of the capital goods

$p_{j}^{\mathrm{e}}=\left(1+\tau_{j}^{\mathrm{e}}\right) \cdot v \cdot p_{j}^{\mathrm{we}}\left(z_{j}\right) \quad$ domestic price of exports

$p_{j}^{\mathrm{a}}=\sum_{i=1}^{s} p_{i}^{\mathrm{ohm}} \cdot a_{i j}+\sum_{i=s+1}^{n} p_{i j}^{\mathrm{hmut}} \cdot a_{i j}+w_{j} l_{j}+q_{j} \cdot k_{j}+p_{j}^{\mathrm{a}} \cdot \tau_{j}^{\mathrm{t}}$,

price-cost identity

$p_{i}^{\mathrm{m}}=\left(1+\tau_{i}^{\mathrm{m}}\right) \cdot v \cdot p_{i}^{\mathrm{wm}} \quad$ domestic price of imports.

As can be seen, we take into consideration various net taxes/subsidies $\left(\tau_{j}^{\mathrm{w}}, \tau_{j}^{\mathrm{e}}\right.$, $\tau_{i}^{\mathrm{m}}$ ad valorem rates), as well as the observed differences in sectoral wage levels $\left(d_{j}^{\mathrm{w}}\right)$ and rates of return on capital $\left(d_{j}^{\pi}\right)$, as common in CGE models. Observe also that the $p_{j}^{\text {a }}$ producers' prices include ad valorem net production taxes $\left(\tau_{j}^{\mathfrak{t}}\right)$ too, which is part of the operating surplus.

For the sake of simplicity, both labour and capital are assumed to be homogeneous, i.e., perfectly mobile across sectors as the other factors of production. Thus, their aggregate demand is simply the algebraic sum of the sectoral demands:

$$
\begin{array}{ll}
\sum_{j} l_{j} \cdot x_{j}=L & \text { total use of labour } \\
\sum_{j} k_{j} \cdot x_{j}=K & \text { total capital demand. }
\end{array}
$$

Capital supply will be assumed to be given exogenously in all closure variants, thus, (M-22) is the condition of equilibrium on capital market. The same holds for (M-21), mutatis mutandis, too, if labour supply $(L)$ is fixed. (If $L$ is not fixed, M-21 defines the demand for labour.)

As can be seen, equations (M01)-(M14), supplemented with equations (M15)(M22), are simply the multi-sectoral equivalents of equations (1)-(9) of the onesector macroeconomic model. We define next the equations equivalent to (10)(14) in the one-sector model.

First, appropriate supplementary variables and equations are introduced to define consumption and investment, as parts of final demand. As in most CGE models, consumer demand is represented by a linear expenditure system (LES), introduced by Stone (1954), which can be expressed as:

$y_{i k}^{\mathrm{c}}=y_{i k}^{\mathrm{e}}+s_{i k}^{\mathrm{cv}}\left(p_{1}^{\mathrm{c}}, p_{2}^{\mathrm{c}}, \ldots, p_{n}^{\mathrm{c}}\right) \cdot C_{k}^{\mathrm{v}} \quad$ consumers' demand (LES),

where consumer's prices contain taxes and subsidies defined by ad valorem consumption tax rates $\left(\tau_{i}^{c}\right)$ in addition to their seller's basic prices:

$p_{i}^{\mathrm{c}}=\left(1+\tau_{i}^{\mathrm{c}}\right) \cdot p_{i}^{\mathrm{chm}} \quad$ consumers' prices.

The $s_{i k}^{\mathrm{cv}}$ functions define the expenditure minimising shares of commodities in variable consumption, whose level is $C_{k}^{\mathrm{v}}$ and $y_{i k}^{\mathrm{e}}$ is the fixed ("committed") 
part of consumer demand. The total consumption of the households by sectors of origin $\left(c_{i}\right)$ can be computed by summing over the consumption of the individual household groups:

$c_{i}=\Sigma_{k} y_{i k}^{\mathrm{c}}$.

In the equilibrium, the composite supply of consumer goods should be equal to the demand for them, where the demand is the sum of the consumption of the inbound tourists $\left(y_{i}^{\mathrm{ct}}\right)$ and the households $\left(c_{i}\right)$ :

$x_{i}^{\mathrm{chm}}=c_{i}+y_{i}^{\mathrm{ct}}$.

$\left(\mathrm{M}-26: x_{i}^{\mathrm{ch}}\right)$

Similarly, the composite supply of investment goods should be equal, in equilibrium, to the total investment demand:

$x_{i}^{\mathrm{bhm}}=\Sigma_{j} b_{i j} \cdot I_{j}$,

$\left(\mathrm{M}-27: x_{i}^{\mathrm{bh}}\right)$

where investment demand is defined as $\Sigma_{j} b_{i j} I_{j}$. The $I_{j}$ variables are the sectoral investment levels and $b_{i j}$ the fixed coefficients of the investment transformation matrix.

In our static model, the sectoral investment levels are determined by assuming fixed sectoral investment shares $\left(s_{j}^{\mathrm{a}}\right)$ in the non-structuralist closures:

$I_{j}=s_{j}^{\mathrm{a}} \cdot I_{1} \quad$ sectoral investment levels,

while in the structuralist closures, the sectoral investment functions will be similar to those used in the one-sector model:

$I_{j}=I_{j}\left(q_{j}\right)=I_{j}^{0} \cdot\left\{q_{j}^{f} q_{j}^{0} \cdot\left(k_{j} / k_{j}^{0}\right)\right\}_{j}^{\delta_{j}} \quad$ sectoral investment functions,

which can represent fixed investment level as well $\left(\delta_{j}=0\right)$. Of course, in this case the total investment level (I) drops out of the model.

The equilibrium condition on other market areas is as follows:

$x_{i}^{\mathrm{ohm}}=\sum_{j} a_{i j} \cdot x_{j}+s_{i}^{\mathrm{g}} \cdot G+y_{i}^{\mathrm{s}} \quad(i=1,2, \ldots, n)$,

$\left(\mathrm{M}-29: x_{i}^{\mathrm{oh}}\right)$

where $s_{i}^{\mathrm{g}}$ represents the commodity-structure of the government consumption and $y_{i}^{\mathrm{s}}$ stands for inventory accumulation.

The balance of trade $\left(D_{\mathrm{e}}\right)$ is defined in the multi-sectoral model by the following equation:

$\Sigma_{i}\left(p_{i}^{\mathrm{wm}} \cdot m_{i}-p_{i}^{\mathrm{we}}\left(z_{i}\right) \cdot z_{i}-p_{i}^{\mathrm{c}} \cdot y_{i}^{\mathrm{ct} /} / v\right)=D_{\mathrm{e}}$ foreign trade balance (deficit). (M-30: $\left.D_{\mathrm{e}}\right)$

Note that fixing the gross trade balance (i.e., the trade deficit without the $-p_{i}^{\mathrm{c}} \cdot y_{i}^{\mathrm{ct} /} v$ term) turns foreign currency reserves into a resource constraint similar to fixed labour and capital. 
The budget balances of the other (domestic) agents are formulated as follows:

$$
S^{\prime \mathrm{w}}=v \cdot D_{\mathrm{e}}+t r^{\mathrm{w}} \quad \text { current account (foreign net savings) }
$$

$\Sigma_{i} p_{i}^{\mathrm{ohm}} \cdot S_{i}^{\mathrm{g}} \cdot G+S^{\mathrm{g}}=\Sigma_{j}\left\{\tau_{j}^{\mathrm{w}} \cdot w \cdot d_{j}^{\mathrm{w}} \cdot l_{j}+p_{j}^{\mathrm{a}} \cdot \tau_{j}^{\mathrm{t}}\right\} \cdot x_{j}+\Sigma_{i}\left\{\tau_{i}^{\mathrm{c}} \cdot p_{i}^{\mathrm{chm}} \cdot x_{i}^{\mathrm{chm}}+\tau_{i}^{\mathrm{m}} \cdot v \cdot p_{i}^{\mathrm{wm}} \cdot m_{i}-\right.$

$\left.-\tau_{i}^{\mathrm{e}} \cdot v \cdot p_{i}^{\mathrm{we}}\left(z_{i}\right) \cdot z_{i}+\Sigma_{j} \tau_{i, j}^{\mathrm{fu}} \cdot p_{i}^{\mathrm{ohm}} \cdot a_{i j} \cdot x_{j}\right\}+t r^{\mathrm{g}} \quad$ government's budget

$p_{j}^{\mathrm{b}} \cdot I_{j}+\sum_{i} s_{i j}^{\mathrm{s}} \cdot p_{i}^{\mathrm{ohm}} \cdot y_{i}^{\mathrm{s}}+S_{j}^{\mathrm{s}}=q_{j} \cdot k_{j} \cdot x_{j}+t r_{j}^{\mathrm{s}} \quad$ sectoral budgets

$\Sigma_{i} p_{i}^{\mathrm{c}} \cdot y_{i k}^{\mathrm{c}}+S_{k}^{\mathrm{h}}=\alpha_{k j}^{\mathrm{w}} \cdot \Sigma_{j} w \cdot d_{j}^{\mathrm{w}} \cdot l_{j} \cdot x_{j}+t r_{k}^{\mathrm{h}} \quad$ household groups' budget, (M-34: $S_{k}^{\mathrm{h}}$ )

where the $\alpha_{k j}^{\mathrm{w}}$ parameters show the individual hoseholds relative share of wage incomes.

The budget identities are thus somewhat different but equivalent to their counterparts in the one-sector model. Observe, for example, that net foreign savings $\left(S^{\mathrm{rw}}\right)$ are determined by the current account, not by the balance of foreign trade (net income from abroad) alone, since net current transfers, $t r^{\mathrm{w}}$, is also taken into account. In addition to households and government, the production sectors appear also as economic actors in the model. They represent the enterprise managers, entrepreneurs, and rentiers, who make production and investment decisions as well as distribute the profits. As a result, unlike in the one-sector model, profit income does not go directly to the households, but through income redistribution.

Each actor (domestic and foreign) has at their disposal a given portion of GDP, which forms their initial (gross or net) income position. Households get hold of gross wages, the sectors retain their gross operating surplus (amortisation plus profit), whereas the government collects taxes and pays subsidies, and foreign net income is formed by the balance of trade. The initial incomes are then transferred from one group to another through different channels. In the CGE models, all sorts of transfer payments are taken into account one by one. (Typical examples of transfers include income taxes, pension contributions, property taxes, investment taxes, social benefits, and the like.) Their net effects on the initial incomes of the agents are denoted by the $t r^{\mathrm{w}}, t r^{\mathrm{g}}, t r_{j}^{\mathrm{s}}$, and $t r_{k}^{\mathrm{h}}$ variables. The value of these agent-specific net transfers can be either positive or negative, but their total sum always has to be zero (one transfers some amount to another actor). The disposable income of the household groups formed in this way can be seen on the righthand sides of the budget equations.

The components of the net transfers are defined in the following ways: $t r^{\mathrm{w}}=v \cdot T^{\mathrm{w}}$, 
where $T^{\mathrm{w}}$ is the net transfer income of the foreign sector assumed to be exogenous in foreign currency.

$\operatorname{tr}^{\mathrm{g}}=\Sigma_{k}\left\{\left(\tau_{k}^{\pi}+\tau_{k}^{\mathrm{s}}\right) \cdot w \cdot \Sigma_{j} \alpha_{k j}^{\mathrm{w}} \cdot d_{j}^{\mathrm{w}} \cdot l_{j}+J_{k}^{\mathrm{d}} \cdot \alpha_{\tau}\right\}-p_{\mathrm{c}} \cdot\left(t_{\mathrm{p}}+t_{t}\right)+\Sigma_{j}\left(J_{j}^{\pi}+p_{\mathrm{c}} \cdot T_{j}\right)-v \cdot T^{\mathrm{w}}$,

where

- $\tau_{k}^{\pi}$ and $\tau_{k}^{\mathrm{s}}$ are the personal income tax rates and employees' social security contribution rates,

- $t_{\mathrm{p}}$ and $t_{t}$ are the households' cash and in-kind benefits in real terms (all routed through the government),

- $T_{j}$ is the net other transfer expenditure of the sectors (also expressed in real terms and assumed to go through the government).

The $J_{j}^{\pi}$ profit tax by sectors and the $J_{k}^{\mathrm{d}}$ disposable income of the households are defined as follows:

$J_{j}^{\pi}=p_{j}^{\mathrm{b}} \cdot J_{j}^{\pi 0} \quad$ profit tax by sectors,

where $J_{j}^{\pi 0}$ are the sector-specific level of the real value of the profit taxes.

$J_{k}^{\mathrm{d}}=\left(1-\tau_{k}^{\pi}-\tau_{k}^{\mathrm{s}}\right) \cdot w \cdot \Sigma_{j} \alpha_{k j}^{\mathrm{w}} \cdot d_{j}^{\mathrm{w}} \cdot l_{j}+p_{c} \cdot \beta_{k} \cdot t_{\mathrm{p}} \quad$ disposable income of the households,

where $\beta_{k}$ coefficients show the relative shares of the individual strata in total cash-benefits.

Using these auxiliary variables, the net transfers of the sectors and households can be formulated as

$t r_{j}^{\mathrm{s}}=-J_{j}^{\pi}-p_{\mathrm{c}} \cdot T_{j}+r_{j} \cdot p_{l}^{\mathrm{b}} \cdot \Sigma_{k} B_{k}^{l}$,

where $r$ represents the housing sector (as the dummy for), $l$ denotes its index, and $B_{k}^{l}$ is the households housing investment expenditure (accounted as transfer to the housing sector) in real terms.

$t r_{k}^{\mathrm{h}}=-\left(\tau_{k}^{\pi}+\tau_{k}^{\mathrm{s}}\right) \cdot w \cdot \Sigma_{j} \alpha_{k j}^{\mathrm{w}} \cdot d_{j}^{\mathrm{w}} \cdot l_{j}+p_{c} \cdot \beta_{k} \cdot t_{\mathrm{p}}+p_{\mathrm{c}} \cdot \phi_{k} \cdot t_{t}-p_{l}^{\mathrm{b}} \cdot B_{k}^{l}-J_{k}^{\mathrm{d}} \cdot \alpha_{\tau}$,

where $\phi_{k}$ coefficients show the relative shares of the individual strata in total in-kind benefits and $\alpha_{\tau}$ is the Johansen-type tax rate (its default value being 0 ), which adjusts in the Johansen closure as $\tau$ did in the one-sector model, and its tax base is the disposable income of the households.

The sum total of net financial savings $\left(\Sigma_{k} S_{k}^{\mathrm{h}}+S^{\mathrm{g}}+\Sigma_{j} S_{j}^{\mathrm{s}}+S^{\mathrm{rw}}\right)$ has to be zero, which secures that total private, public, and foreign savings plus the retained 
earnings by the sectors will be equal to investments. It can be shown that equation system (M-01)-(M-34) fulfils the requirement of Walras' law.

Equation (M-41) establishes the relationship between households' savings $\left(S^{\mathrm{h}}\right)$ and disposable income by means of a savings rate $\left(\delta_{k}\right)$ :

$S_{k}^{\mathrm{h}}=\delta_{k} \cdot J_{k}^{\mathrm{d}} \cdot\left(1-\alpha_{\tau}\right) \quad$ households' total savings.

$\left(\mathrm{M}-41: C_{k}^{\mathrm{v}}\right)$

In the one-sector macroeconomic model, we distinguished savings rates from wages and profits. This latter relationship, used in CGE models, is a more realistic way to represent the savings behaviour since most households receive wages as well as profit shares or rents. Savings rates differ across income groups rather than depend on the source of income.

In the multi-sectoral model, the real exchange rate will be defined as $v_{\mathrm{r}}=v \cdot \Sigma_{i} p_{i}^{\mathrm{we}}\left(z_{i}\right) \cdot z_{i} / \Sigma_{i} p_{i}^{\mathrm{h}} \cdot z_{i} \quad$ real exchange rate.

Observe that the equation system (M-01)-(M-42) is equivalent to equations (1)-(15) of the one-sector model.

Finally, the price level in running simulations with the CGE model will be fixed by the following equation:

$p_{\mathrm{c}}=\sum_{i} p_{i}^{\mathrm{c}} \cdot c_{i} / \sum_{i} p_{i}^{\mathrm{c} 0} \cdot c_{i} \quad$ consumers' price index,

which will be set to unity, in a way similar to $p^{\mathrm{hm}}=1$ in the one-sector model:

$p_{\mathrm{c}}=1$.

$(\mathrm{M}-44: v)$

Similarly, we introduce the average investment price index as

$p^{\mathrm{b}}=\left(\sum_{i} p_{i}^{\mathrm{bhm}} \cdot \Sigma_{j} b_{i j} \cdot I_{j}\right) / \Sigma_{j} I_{j} \quad$ price index of the capital goods.

With the model defined by the above equations, one can easily and quite closely replicate the simulations done with the one-sector model under the Neo-classical, Johansen, Keynesian, and Neo-Keynesian closure rules. In order to implement the structural closures, the model has to be modified. Equation (M-28) is replaced by (M-28'), containing sectoral investment functions and total investment, $I$ is dropped as a variable. New variables and equations have to be introduced, as in the case of the one-sector model. Potentially variable profit mark-up rates, $\alpha_{\pi} \cdot c_{j}^{\pi}$ are introduced, where $\alpha_{\pi}$ is the general level of the profit mark-up (equal to 1 in the base) and the $c_{j}^{\pi}$ parameters denote their sectoral differences (their values are set at their observed base level). Parallel to that, the unit gross operating surplus $\left(q_{j} \cdot k_{j}\right)$ has to be accordingly redefined and replaced in equations (M-19) and (M-34) as $p_{j}^{\mathrm{b}} \cdot r_{j}^{\mathrm{a}} \cdot k_{j}+\alpha_{\pi} \cdot p_{j}^{\mathrm{a}} \cdot c_{j}^{\pi}$, where the first term represents the amortisation and the second the profit (net operating surplus). 
Next, the relationship between the general level of the net rate of return $(\pi)$ and the profit mark-up $\left(\alpha_{\pi}\right)$ has to be specified, as it was done by equation (16) in the one-sector model. In the multi-sectoral model, the following two equations will do the same:

$\begin{array}{lll}\pi \cdot d_{j}^{\pi} \cdot p_{j}^{\mathrm{b}} \cdot k_{j}=\alpha_{\pi} \cdot p_{j}^{\mathrm{a}} \cdot c_{j}^{\pi} & \text { sectoral rate of return differences } & \left(\mathrm{M}-46: d_{j}^{\pi}\right) \\ \sum_{i} d_{i}^{\pi}=\Sigma_{i} d_{i}^{\pi 0} & \text { normalisation of the rates of return. } & \left(\mathrm{M}-47: \alpha_{\pi}\right)\end{array}$

\subsection{Closure options in and simulations with the CGE model}

The equation system (M-01)-(M-45) is thus the multi-sectoral counterpart of equations (1)-(15) in the case of the one-sector model. In all multi-sectoral simulations $G$ will be exogenous, whereas all variables associated with the equations (M-01)-(M-45), except for $L, D_{\mathrm{e}}$ and $v_{\mathrm{r}}$, which are associated to (M-21), (M-30) and (M-42), respectively, will be endogenous. The remaining degree of freedom is thus 3 . In addition to $L, D_{\mathrm{e}}$ and $v_{\mathrm{r}}$, variables $I, w, \alpha_{\mathrm{w}}$, and $\alpha_{\tau}$, which were not associated with any equation, make up thus seven macro and auxiliary variables from among which three further endogenous variables can be chosen, in order to make the system well determined in the case of the Neo-classical, Johansen, Keynesian and the Neo-Keynesian closures.

In the case of the Structuralist closures, as described above, the model has to be modified. $d_{i}^{\pi}$ and $\alpha_{\pi}$ appear as additional variables, together with two additional equations. $d_{j}^{\pi}$ is added to the list of the always endogenous variables, and $\alpha_{\pi}$, associated with (M-47), to the former list of the potential endogenous variables. Since $I$ is at the same time dropped from the model (or, alternatively, it becomes an always endogenous variable, associated with identity $I=\Sigma_{j} I_{j}$ ), the number of potential endogenous variables remains seven. The degree of freedom increases by one. Four more endogenous variables have to be chosen out of the seven candidate variables and the remaining three fixed, in order to close the model. So, the closure options are the same as in the case of the one-sector model (see in Table 1), the only differences would be in the notation: $\tau$ and $c^{\pi}$ are replaced by $\alpha_{\tau}$ and $\alpha_{\pi}$. 


\section{REPLICATED SIMULATIONS WITH A CGE MODEL}

We have thus repeated the simulations with a five-sector, ${ }^{9}$ three-household CGE model, which was calibrated on the bases of the same data set as the one-sector model. We will refer to our numerical model as CGE-mini. As demonstrated in the previous section, the structure of the CGE-mini is in some aspects different from the stylised one-sector model presented above.

Because of these and other differences, it was not possible to reproduce exactly the benchmark values of the macroeconomic indicators of the one-sector model either. What impedes further the comparison of the results gained from the onesector macro model and the five-sector CGE model is that the macro variables are sectoral aggregates, which alone can be a serious distorting factor. Due to these difficulties, the reproduction of the scenarios of the one-sector model with CGEmini required occasionally in-depth considerations too.

The results of 12 selected replicated simulations can be seen in Table 5. The results of the simulations omitted are quite similar to their one-sector counterpart. Note that in the CGE model the export, unlike in the one-sector model, does not contain the turnover of tourist revenues, it is part of private consumption. Therefore, the volumes of $Z$ and consequently of $X^{\mathrm{h}}$ and $X^{\mathrm{hm}}$ differ from their counterparts in the one-sector model. Note also that when gross trade deficit is fixed, the trade deficit $\left(D_{e}\right)$ might still vary slightly due to the changing foreign currency value of the fixed consumption of the inbound tourists.

It suffices to comment only briefly on the observable differences between the results obtained from the one- and the five-sector model. In the case of a $5 \%$ increase in $G$, the level of employment and the aggregate volume of production changes in the same direction as in the one-sector model, but more moderately in the fivesector model. The same applies to the aggregate volume of exports and imports, as well as to the general wage and profit rates, which change even more moderately.

In the case of a $2 \%$ increase in import prices, one can observe more significant differences between the results obtained by the two models. It is understandable because changes in the import prices affect the input structures and consumption patterns too. The Neo-Keynesian closures produce surprisingly more drastic changes than the one-sector model, some variables move even in opposite direction than in the one-sector model. The Structuralist closures (the first in the case of fixed trade balance, the second in the case of fixed real exchange rate) also provide results qualitatively rather different from those obtained in the one-sector model.

9 The five aggregate sectors are as follows: raw materials (including the energy sectors), manufacturing (without food industry), food and agriculture, material services, and non-material services. 


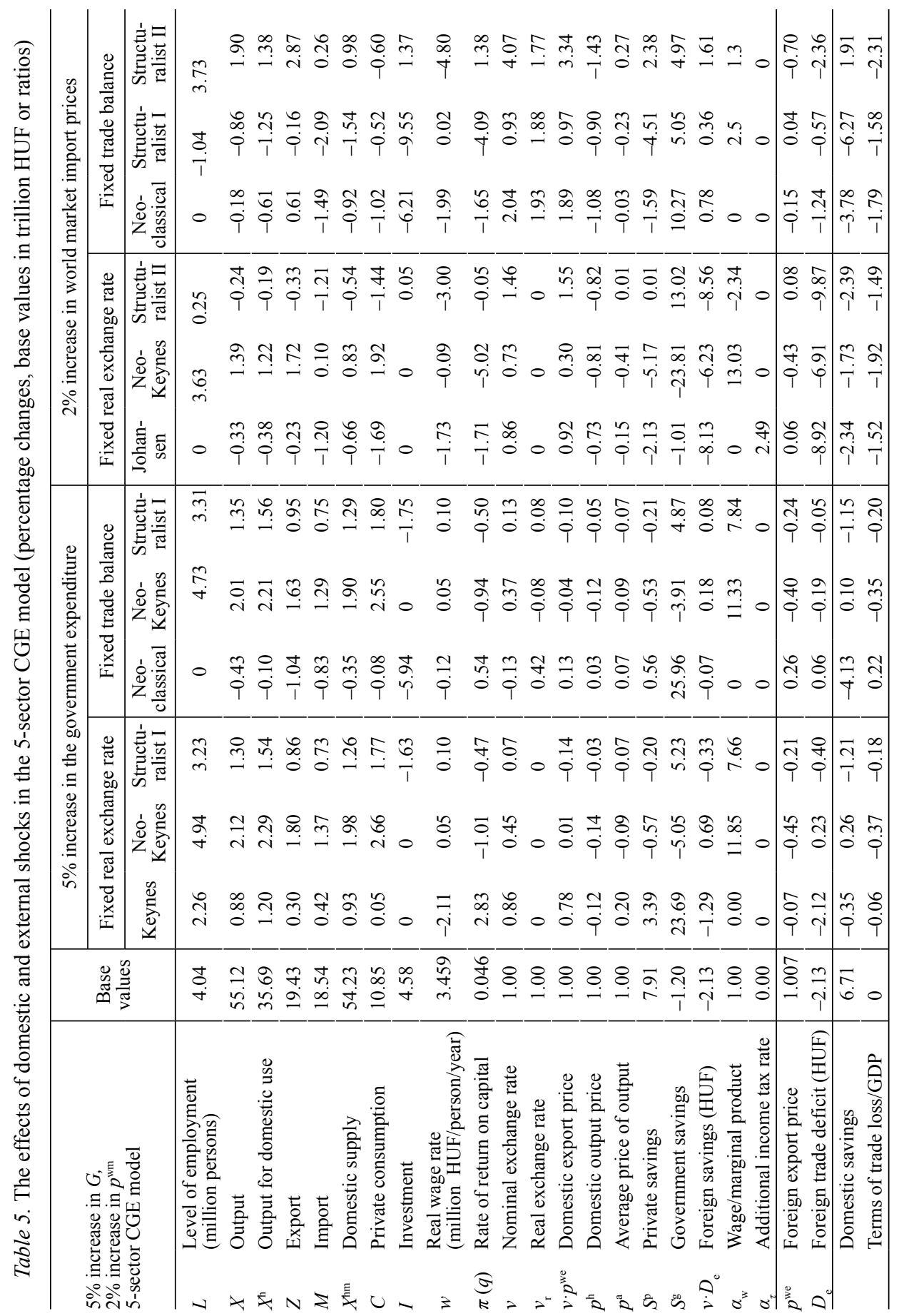


Table 6. Change in import demand by sector, \%

\begin{tabular}{l|c|c|c|c|c|c}
\hline Scenario $\backslash$ Sector code & $\begin{array}{c}\text { Raw } \\
\text { materials }\end{array}$ & $\begin{array}{c}\text { Manufac- } \\
\text { turing }\end{array}$ & $\begin{array}{c}\text { Food and } \\
\text { agricul- } \\
\text { ture }\end{array}$ & $\begin{array}{c}\text { Material } \\
\text { services }\end{array}$ & $\begin{array}{c}\text { Non-mat. } \\
\text { services }\end{array}$ & Total \\
\hline Overall 2\% price increase & -3.14 & 3.25 & 1.62 & 0.32 & -1.01 & 1.25 \\
\hline $8.8 \%$ in raw material prices & -5.68 & 2.91 & 2.56 & 1.33 & 0.17 & 0.66 \\
\hline Difference & -2.54 & -0.34 & 0.94 & 1.01 & 1.18 & -0.59 \\
\hline
\end{tabular}

It is also important to note that one could differentiate the expected changes in parameters across sectors in a multi-sectoral model, which would produce even more different results for otherwise similar scenarios than the one-sector model. For example, if one assumed instead of the general $2 \%$ increase in the import prices that only the price of the raw materials increased by $8.8 \%$, which would generate the same $2 \%$ increase in the aggregate import price index, then the structural effects would be more pronounced. For example, in the Neo-Keynesian closure, in the case of fixed trade balance, the sectoral imports would change the way as shown in Table 6.

One can see that concentrating the assumed import price changes to one sector resulted in an only half as large increase in total import, for which only two sectors were responsible (understandably the raw materials and less intuitively the manufacturing products).

We should warn the reader that our necessarily limited number of simulations served only demonstrative purposes. Only one exogenous variable was assumed to change in each of them. In other words, we did not attempt to formulate changes consistent (both theoretically and empirically) in all important exogenous categories as it should be done in a more realistic scenario package. Our aim was only to replicate the simulations done with the one-sector model.

\section{CONCLUDING REMARKS}

In this paper, the problem of macro closure was revisited, a problem that arises in one-period general equilibrium models if they are based strictly on neo-classical assumptions. Following and extending the earlier literature on the subject, alternative "closure rules" were discussed, and these can be used to allow for autonomous investment decisions and other more realistic adjustment mechanisms in such models.

In a one-sector model, it was demonstrated how the effects of exogenous shocks depend on the adjustment mechanisms one assumes to be operating. Running similar simulations with a complex CGE model, based on a 2010 Hungarian 
database compiled by us, we demonstrated the robustness of the model framework, i.e., that applying the same closure rule, one will get roughly the same results for the macroeconomic aggregates from the one-sector and multi-sector CGE model. The results gained from assuming different closures will, however, yield characteristically different results.

We have illustrated the limitations of the simple macroeconomic model, and its inability to project the changes in key macro variables well enough. A CGE model provides not only more realistic predictions, but also clearer explanations of the mechanisms that lie behind the projected changes. In particular, we pointed out that a multi-sectoral model may use more elaborate technology, income distribution and demand functions, and take into account different exogenous changes affecting various sectors. All these features warrant different and more trustable results from a multi-sectoral than an aggregate macroeconomic model.

The lack of sufficiently reliable economic theories prevents model builders from formulating enough consistency criteria (equations) to match all the potential variables of the model. This is why some have to be set exogenously. The emerging dilemma of which variables should be exogenous and/or endogenous can be perceived as the generalisation of the classical closure problem. The given policy problem being analysed not only limits the choice of macro closure, but also suggests what particular closure rules could or should be chosen. When doubts remain, the modeller should test the model by choosing alternative closure options, on the basis of which she/he can formulate alternative scenarios, in which the exogenous variables are better harmonised.

\section{REFERENCES}

Bergman, L. - Jorgenson, D. - Zalai, E. (eds) (1990): General Equilibrium Modeling and Economic Policy Analysis. New York: Basil Blackwell.

Decaluwe, M. - Martens, A. - Monette, M. (1988): Macro Closures in Open Economy CGE Models: A Numerical Reappraisal. International Journal of Development Planning Literature, 3(2): 69-90.

Dervis, K. - de Melo, J. - Robinson, S. (1982): General Equilibrium Models for Development Policy. Cambridge: University Press.

Devarajan, Sh. - Go, D. S. - Lewis, J. D. - Robinson, Sh. - Sinko, P. (1994): Policy Lessons from a Simple Open-Economy Model. Policy Research Working Paper Series 1375, The World Bank.

Dewatripont, M. - Michel, G. (1987): On Closure Rules, Homogeneity and Dynamics in Applied General Equilibrium Models. Journal of Development Economics, 26(1): 65-76.

Hertel, T. W. (ed.) (1997): Global Trade Analysis: Modelling and Applications. Cambridge: University Press.

Hungarian Central Statistical Office (2012): National Accounts 2009-2011. Budapest.

Hungarian Central Statistical Office (2012): Dissemination Database. Symmetric Input-Output Tables, Supply and Use Tables. Budapest. 
Johansen, L. (1960): A Multi-Sectoral Study of Economic Growth. Amsterdam: North-Holland.

Kaldor, N. (1956): Alternative Theories of Distribution. Review of Economic Studies, 23: 94-100.

Keynes, J. (1936): The General Theory of Employment, Interest and Money. London: Palgrave Macmillan.

Limão, N. (2008): Optimal Tariffs. In: Durlauf, S. N. - Blume, L. E. (eds): The New Palgrave Dictionary of Economics. London: Palgrave Macmillan.

Pasinetti, P. (1962): Rate of Profit and Income Distribution in Relation to the Rate of Economic Growth. Review of Economic Studies, 29: 267-279.

Rattsø, J. (1982): Different Macro Closures of the Original Johansen Model and Their Impact on Policy Evaluation. Journal of Policy Modeling, 4(1): 85-97.

Robinson, S. (1991): Macroeconomics, Financial Variables, and Computable General Equilibrium Models. World Development, 19(11): 1509-1525.

Robinson, S. (2006): Macro Models and Multipliers: Leontief, Stone, Keynes, and CGE Models. In: Janvry de, A. - Kanbur, R. (eds): Poverty, Inequality and Development: Essays in Honour of Erik Thorbecke. Springer.

Sen, A. (1963): Neo-Classical and Neo-Keynesian Theories of Distribution. Economic Record, 39: 53-64.

Shoven, J. B. - Whalley, J. (1992): Applying General Equilibrium. Cambridge: University Press.

Stone, R. (1954): Linear Expenditure Systems and Demand Analysis: An Application to the Pattern of British Demand. The Economic Journal, 64(255): 511-527.

Taylor, L. (1990): Structuralist CGE models. In: Taylor, E. (ed.): Socially Relevant Policy Analysis. Cambridge, Mass., U.S.A.: MIT Press.

Taylor, L. - Lysy, F. J. (1979): Vanishing Income Redistributions: Keynesian Clues about Model Surprises in the Short Run. Journal of Development Economics, 6: 11-29.

Thissen, M. (1998): A Classification of Empirical CGE Modelling. SOM Research Report, 99C01. University of Groningen, The Netherlands.

Tobin, J. (1971): Essays in Economics: Macroeconomics. Chicago: Markham Publishing.

Zalai, E. (2004): The von Neumann Model and the Early Models of General Equilibrium. Acta Oeconomica, 54(1): 3-38.

Walras, L. (1874): Élements d'économie politique pure; ou théorie de la richesse sociale. Paris. 